\title{
Beyond the farmer and the butcher: Institutional entrepreneurship and local meat
}

\author{
Lauren Gwin ${ }^{\text {* * }}$ \\ Oregon State University
}

Arion Thiboumery ${ }^{\mathrm{b}}$

Iowa State University

Submitted August 23, 2013 / Revised November 7, 2013 / Accepted December 3, 2013 /

Published online March 6, 2014

Citation: Gwin, L., \& Thiboumery, A. (2014). Beyond the farmer and the butcher: Institutional

entrepreneurship and local meat. Journal of Agriculture, Food Systems, and Community Development,

4(2), 81-96. http://dx.doi.org/10.5304/jafscd.2014.042.007

Copyright (C) 2014 by New Leaf Associates, Inc.

\begin{abstract}
Increased demand for local food has led to calls for additional supply-chain infrastructure to move products from farm to market. Meat and poultry are highly perishable, rigorously regulated products that require a complex chain, and processing is often said to be the weak link for local meats. Commitment from producers and meat buyers is essential to the persistence and expansion of

a * Corresponding author: Lauren Gwin, 107 Crop Science Building, Oregon State University, Corvallis, Oregon 97331 USA; +1-541-737-1569; lauren.gwin@oregonstate.edu

b Arion Thiboumery, 705 Cannon Industrial Boulevard, Cannon Falls, Minnesota 55009 USA; +1-507-263-3618; arion@iastate.edu

Author note: The authors founded and coordinate the Niche Meat Processor Assistance Network (NMPAN), discussed in this article. NMPAN is a community of practice through eXtension.org, the online presence of the land-grant university system, and is housed at Oregon State University. Earlier versions of the case studies in this paper were published by the authors under a cooperative agreement with the U.S.

Department of Agriculture Economic Research Service.
\end{abstract}

processing capacity, but nonmarket actors can provide critical technical support and facilitate innovation that strengthens this sector. We present four collaborative efforts, three regional and one national, that focus on processing with the goal of expanding the local meat sector. These efforts harness the experience and expertise of a variety of partners, both public-sector and private, and provide information, guidance, and direct technical assistance. They also collaborate and cooperate with each other in a national peer-learning community, sharing and generating innovative knowledge, tools, and strategies. Tentative evidence of increased processing capacity, producer access to processing, and local meats marketing, while certainly not solely attributable to these efforts, suggests their value.

\section{Keywords}

institutional entrepreneur, local food systems, local meat processing, local meats, local poultry, professional structures, reference networks, small farms, small meat processors 


\section{Introduction}

As demand for local food grows (Low \& Vogel, 2011; Martinez et al., 2010), those involved with bringing it to market point to a need for additional post-farmgate infrastructure (Bloom \& Hinrichs, 2010; Buck, 2011; Cantrell \& Lewis, 2010; Morley, Morgan, \& Morgan, 2008; Western SARE, 2013). Meat and poultry, as highly perishable products, require a complex and rigorously regulated supply chain, and processing is often said to be the weak link (Food and Water Watch, 2009; Fromartz, 2012; Zezima, 2010). Facilities may be located far from farms and ranches, have limited availability during peak livestock finishing periods (especially the fall for ruminant livestock), or lack the inspection status, skills, or services desired by producers. Yet meat processing is a high-risk, thin-margin business, and small processors often lack the steady, consistent business needed to be profitable while providing high quality, customized services (Gwin, Thiboumery, \& Stillman, 2013; DeHaan, 2011; Lewis \& Peters, 2011; Raines, 2011).

Strengthening this link in the chain to allow more local meat to flow to market requires commitment from livestock producers on one side and meat buyers (end consumers or the retailers, restaurants, food service, and others that sell to end consumers) on the other to provide the steady business - enough livestock, enough of the time - that processors need for financial viability. Processors are then able to commit to providing high quality services and expanding capacity to meet producer needs (Gwin, Thiboumery, \& Stillman 2013). Without such commitments, the processors necessary for local meats to get to market will struggle to persist, let alone to expand capacity.

However, asserting that market actors and business commitments are essential to filling apparent infrastructure gaps to bring more local food to market is not the same as saying "the market will sort it out." On the contrary, our research on innovations in local meat and poultry processing suggests that nonmarket actors individuals and organizations, typically but not exclusively from universities, public agencies, and nongovernmental organizations (NGOs), who provide external support for market actors and transactions - play an important role in bringing more local meat and poultry to market. Nonmarket actors foster innovation by facilitating connections and peer-to-peer learning not only between livestock producers and processors but all along local meat supply chains. They also learn from each other, pulling and adapting innovations from one region to another, generating new knowledge and approaches as they go.

This paper examines the role of such nonmarket actors in creating and strengthening communication, collaboration, and coordination related to processing as a link in local meat and poultry supply chains. We present data from case studies of four collaborations, three regional and one national, involving public- and private-sector partners, that provide information, guidance, and technical assistance related to local meats processing. Their focus on processing occurs within a farm-to-plate context: efforts to shore up and expand processing capacity are motivated explicitly by the goal of allowing more livestock producers to bring more local meat and poultry to more consumers. We use three useful concepts - professional structures, reference networks, and institutional entrepreneurship - to frame our discussion of these collaborations, their current accomplishments, and their potential. Tentative evidence of increased processing capacity and producer access to processing, while not attributable to these initiatives only, suggests their value. They not only provide valuable support and technical assistance but also appear to be transforming how local producers and their processors work together and, further, how agencies and organizations do the work of building and strengthening local meat and poultry supply chains.

In the rest of the introduction, we explain our research methods. In section two, we draw on existing theories of innovation and knowledge generation as a framework for our empirical data, which we present in section three. In section four, we revisit our framework and conclude with recommendations for practitioners and suggestions for future applied research.

\section{Methods}

The data and analysis presented here are part of a 
larger research project on barriers, innovations, and opportunities related to local meat and poultry processing. This paper draws on several sources of empirical data. We conducted multiple interviews by phone and in person from 2009 to 2013 with eight people with central leadership roles in the three regional collaborations discussed here. Interviews were semistructured, allowing room for emergent topics of interest and relevance. Questions focused on the collaboration's history and motivation, goals, structure, participants, activities, and accomplishments. (All quotations in this paper are from the interviews, unless otherwise noted.) We supplemented interviews with follow-up email and phone conversations to clarify and update information; analyzed written reports and other materials generated by these collaborations as part of their processing-related work; and attended and participated in initiatives designed and implemented by all four collaborations (advisory-board conference calls and in-person meetings, two regional conferences, conference presentations, and a technical assistance project). The paper, specifically the section on the national network but also more generally, is also informed by years of participant observation. We have worked on this issue for more than a decade each, as graduate students, extension professionals, academic researchers, and processing plant personnel, and together founded and coordinate the Niche Meat Processor Assistance Network (NMPAN), described here. We do not suggest that our data and analysis represent all nonmarket support related to small processors or local meat and poultry. We also do not describe all nonmarket actor collaborations currently focused on local meats processing in the U.S.; a comprehensive list is beyond the scope of this paper. We also recognize that the three regional efforts we describe are located in the eastern U.S. Related work in the West is ongoing (e.g., University of California Cooperative Extension, 2013), but there are additional challenges for both local meats and supportive nonmarket actors where travel distances are greater and urban markets more dispersed, though the need for supply chain commitments remains the same. An analysis of geographic variation in this work is beyond the scope of this paper. Here, we focus on a few specific collaborations we believe have been particularly effective and can provide useful lessons for others aspiring to do similar work. In addition, we contribute analytic observations to existing theories about the role of nonmarket actors in supporting and reshaping local food systems.

\section{Framing the Work of Nonmarket Actors in Local Food and Local Meats}

As others have convincingly argued, nonmarket actors provide critical support for the expansion and evolution of local food systems by helping to navigate and remake the social, economic, and political context and conventions in which local food systems operate and facilitate the diffusion of innovation (Dunning, Creamer, Massey Lelekacs, O'Sullivan, Thraves, \& Wymore, 2012; Fairfax, Dyble, Guthey, Gwin, Moore, \& Sokolove, 2012; Hinrichs \& Charles, 2012). Dunning and coauthors identify local food systems as an emerging institutional field and usefully describe university cooperative extension's role in developing local food systems as "institutional entrepreneurship." This concept refers to the "activities of actors who have an interest in particular institutional arrangements and who leverage resources to create new institutions or to transform existing ones" (Maguire, Hardy \& Lawrence, 2004, p. 657). For Dunning and co-authors, cooperative extension agents, as institutional entrepreneurs, "harness resources and opportunities that exist in the relational communities in which they are embedded, catalyze collaboration across actor networks, and thus spur action that otherwise would not have occurred" (Dunning et al., 2012, p. 104).

When institutional entrepreneurs catalyze collaboration across networks, they facilitate interaction and information-sharing that can lead to the creation and use of new technical knowledge (Wolf, 2008). As Wolf notes, interaction is particularly critical for the creation of context-specific and localized knowledge. He identifies "reference networks" and "professional structures" as institutions that together drive innovation through synthesis and codification of practitioner knowledge. A professional structure is a set of organizations, formal and informal, that "coordinate[s] activity 
and investment in order to advance political, economic, social, and technical interests of a class of individuals or entrepreneurs" (Wolf, 2008, p. 203); reference networks are databases that facilitate collective learning outside the boundaries of a given organization (Wolf, 2008). As a way to explain the creation and transfer of knowledge and innovation, professional structures are similar to communities of practice, groups of people who interact regularly to enhance their knowledge and expertise around a shared problem or interest within a specific domain of knowledge (Wenger, McDermott, \& Snyder, 2002).

The collaborations described in this paper operate as both professional structures and communities of practice to varying degrees, backed up by a reference network. They operate on multiple levels, within their regions and nationally, to improve the landscape of meat processing and expand the local meat sector. Whether they can actually be considered institutional entrepreneurs depends on whether they are changing institutions. Providing practical guidance and technical knowledge to enhance local meat and poultry processing capacity and producer access to it is valuable and needed work; in and of itself, it does not necessarily change institutions. However, based on initial evidence of their impact, we argue that the collaborations we describe here not only serve as professional structures but also are transforming institutions, notably the working relationships between local producers and local processors and the way that their own agencies and organizations participate in building and strengthening local meat and poultry supply chains. To borrow terms from Dunning and co-authors, they are harnessing resources and opportunities in their communities, catalyzing collaboration, and spurring action that would not otherwise occur.

\section{How Nonmarket Actors Strengthen Local Meats Processing: Case Studies}

As noted, the four efforts described here focus on enhancing local meats processing as a way to enhance local meat supply chains. Three are regional, operating primarily in Vermont, North Carolina, and New York, but blurring over state lines in each case. The fourth is a national network in which all three regional collaborations also participate.

These are certainly not the first nonmarket actors to provide support for small-scale processors or local meat producers. In many states, universities have long provided technical support and education for small processors related to food safety and regulatory compliance (e.g., Flowers \& Cutter, 2005), business planning (e.g., Holcomb, Flynn, \& Kenkel, 2012), and daily operations (e.g., Thiboumery, 2008). Processors have technical assistance and networking opportunities through state, regional, and national trade associations. The U.S. Department of Agriculture's Food Safety and Inspection Service has a Small and Very Small Plant Outreach office, and many state meat and poultry inspection agencies provide technical assistance to plants they regulate. In a different realm, the increasing array of "how to" resources related to local foods includes those focused on local meats, from elements of USDA's Agricultural Marketing Service and the "Know Your Producer Know Your Food Compass" (USDA, n.d.) to niche livestock marketing guides written by cooperative extension for producers (e.g., Goodsell \& Stanton, 2010).

The efforts we describe here are similar in several ways: they provide information and technical assistance; involve cooperative extension and public agencies, including a number of entities listed above; and learn from their peers in other regions, to share ideas, best practices, and pitfalls. But they are different in several key ways. First, while the underlying motivation is to increase opportunities for producers and consumers related to local meat and poultry, the collaborators have realized the importance of working directly with processors to solve processors' problems, rather than, for example, simply assuming that processing is "the problem" for local meat and new plants are "the solution." They are working to understand and then address the real drivers behind the perceived lack of processing. And they actively engage processors within a farm-to-plate context: their networking, technical assistance, and education efforts reach across and engage the whole supply chain, not just the practitioners (producers, processors, distributors, marketers, and so on) but 
also the range of nonmarket actors who traditionally focus on one or two links of that chain (livestock extension specialists, meat scientists, business management trainers, and so on). This approach is transformative.

\section{Vermont Meat Processing Working Group}

In Vermont, keeping existing processors in business has become a priority, in large part due to the work of the state's Meat Processing Working Group. Vermont livestock producers, policymakers, and others had long been convinced that processing, constrained by regulation, was limiting local market opportunities for meat producers. Two farming and food initiatives, for the state and for New England, kicked off efforts in 2009 with meat processing as a priority.

The coordinator of the New England meat processing working group, Chelsea Bardot Lewis, decided to test these assumptions and interviewed 20 of the 28 inspected processors in New England. "After the first three, it was clear that their biggest problem wasn't regulation," she explained. "It was not having enough supply, enough animals over the course of the year." Finding, affording, and keeping a trained workforce was also a core challenge, and challenges related to both throughput and labor are compounded by seasonality (Lewis \& Peters, 2011). A survey of Vermont processors conducted by the Northeast Organic Farming Association revealed similar results: the seasonality of demand for processing was a critical problem, given the need for year-round work, and storage and cut-and-wrap capacity appeared to be much tighter bottlenecks than slaughter capacity.

The research made clear that addressing inefficiencies in current processing infrastructure was likely to be more effective than trying to add plants in places that appeared to be "processing deserts." Lewis explained, "Everyone wants some graphic that shows here's where the production is, here's where the processors are, and here's a gap, so let's put a plant here. That's not the right approach. We need to move away from that topdown assessment and start from the bottom up."

The Vermont Agency of Agriculture, Food, and Markets convened a statewide meat processing task force, led by Lewis, who is now at that agency.
Members are both public and private sector and include the Farm Viability Program, the Agricultural Development Program, the Agricultural Credit Corp., University of Vermont extension, the Northeast Organic Farming Association, Rural Vermont, the Castanea Foundation, and the state meat inspection program.

In 2010, the task force started "from the bottom up" in three ways: a financial assessment of the state's small processors; technical assistance for and investment in existing processors; and a series of producer-processor workshops. The financial assessment was designed to understand small processor management strategies, develop "benchmark" indicators for the sector, give processors metrics to assess financial health, and learn what long-term technical assistance would help processors become profitable, expand, or meet other goals. The assessment revealed that processors had thin operating margins, with labor and energy the primary costs; were undercapitalized and carried substantial debt; and did not track productivity or collect financial data to evaluate their businesses.

In 2011 the Vermont state legislature responded with US $\$ 50,000$ in matching funds for capacity improvements. Two processors received grants: a rail system renovation to increase capacity 40 percent, and a hot-water tank and equipment for a pasteurizer. A third, a "Farm to Plate" grant, allowed the Mad River Food Hub, a new shared storage, processing, and distribution facility, to add federally inspected meat-cutting rooms to ease the cut-and-wrap bottleneck. In all three cases, task force members provided planning and technical assistance. The state's Farm Viability and Agriculture Development Programs also began offering processors one-on-one technical assistance regarding expansion planning, access to capital, and transition planning.

The workshop series addressed the need to improve producer-processor relationships, critical to enhancing business commitments, and highlighted processor expertise. At the first session, a processor taught carcass assessment and grading, yield tracking, and how to achieve consistent carcass quality throughout the year. The second session covered regulations and third-party certifications related to animal welfare and humane 
handling, both on-farm and at the processor. At the other two sessions, producers and processors shared marketing strategies.

To address the problem of highly seasonal demand, the task force began working with producers on collaborative marketing arrangements to scale up production and spread it over the year. To increase the labor pool, a meat-cutter training program is being planned in partnership with technical education centers, the state labor department, and the state economic development agency. As another way to enhance processor viability, a "Know Your Processor" marketing campaign will use market research on consumer valuation of meat processing in the value chain to raise the profile of the state's processors and help them market their added value (e.g., humane handling and cutting quality and consistency).

The task force is also creating and nurturing professional networks to facilitate peer learning across the state and region. First, they helped rebuild the state's nearly defunct Meat and Poultry Processors Association and in 2012 took the association's leadership to a national meat-processing convention to meet leaders from other state and regional trade associations. Second, in partnership with colleagues, producers, processors, and other regional stakeholders, they hosted the first New England Meat Conference in 2013, which drew 300 attendees from farming, processing, retail, restaurants, distribution, public agencies, and nonprofits. While processing and processors were the central theme of the conference, the title explicitly recognizes the farm-to-plate approach. An extension specialist participant noted the "cross-fertilization between people representing different sectors of the meat industry. Producers were sitting with processors and butchers and distributors - all were asking great questions, and all were honestly listening to one another and learning from each other's expertise" (Zipparo, 2013).

At this writing, the task force is planning to recruit and facilitate management teams of experienced processors and targeted consultants to provide guidance and mentoring for two processing start-ups. Task force leaders are using the national network (described below) to plan and implement this project, seeking insights from peer efforts in other regions.

The local meat sector in Vermont appears to have expanded significantly since 2010, when the task force began its work. Randy Quenneville, meat programs section chief with the Vermont Meat Inspection Service and a member of the meat processing task force, reported rapid expansion of processing capacity in the state: the number of state-inspected plants has grown to 16 , from three in 2005; several state-inspected plants are transitioning to USDA-inspected status in order to allow interstate shipment; the innovative Mad River Food Hub, a commercial kitchen, is now USDAinspected to do value-added meat processing; producers are committing to slaughter dates into the coming year, to provide inspected plants with consistent throughput; and three custom-exempt ${ }^{1}$ processors have upgraded to state inspection within the last year (R. Quenneville, personal communication, Aug. 7, 2013). While consumer demand and producer interest are likely the primary drivers, the work of the task force has provided the needed support for the processing capacity that links the two together.

\section{North Carolina: NC Choices}

In North Carolina, efforts to bring more local meat to market have generated new support for the state's small processors. NC Choices, an initiative of the Center for Environmental Farming Systems (CEFS), is leading this work, and its two staff collaborate with agency and nonprofit partners around the state. CEFS, established in 1994 by North Carolina State University, North Carolina Agricultural and Technical State University, and the North Carolina Department of Agriculture and Consumer Services, provides agricultural research, extension, and education (CEFS, n.d.). CEFS launched NC Choices in 2005 with support from the Kellogg Foundation and initially focused on developing market opportunities for pasture-based pork producers through an online directory, meat-

\footnotetext{
${ }^{1}$ Custom-exempt processors are not continuously inspected by USDA or an "equal to USDA" state inspection program; the meat cannot be sold and is for the use of the owner of the animal. For more about meat processing regulations, see Johnson, Marti, \& Gwin, 2012.
} 
buying clubs, and wholesale marketing guidance. This work, coupled with what they were hearing from statewide local food system meetings, suggested a need for more meat processing and valueadded processing in particular. Producers wanted to sell sausage, bacon, and cured meats, but of the state's 20 small-scale processors, including customexempt, USDA-inspected, and state-inspected plants, only a few offered value-added processing and the quality cutting, packaging, and labeling services producers needed to expand beyond very basic direct sales. "We found ourselves asking," said Jennifer Curtis, then NC Choices director, "how can we help on processing?"

Three sequential projects involving processing, distribution, and retail led NC Choices to its strategic decision to focus attention and resources on education and technical assistance for existing processors. First, Curtis convinced the owners of a small, USDA-inspected, value-added processor, Acre Station Meat Farm (ASMF), that their plant had the capacity for and could financially benefit from offering fee-for-service processing in addition to handling their own product. This gave many NC producers their first access to inspected valueadded processing. NC Choices brought one of ASMF's owners to the state's largest sustainable agriculture conference in 2008 , paying his way and introducing him to more producers and meat buyers who needed his services; he was the first small processor ever to attend that conference. NC Choices also helped ASMF write grants for new equipment and business development. ASMF now processes for 80 different producers; has brought on Whole Foods as a major customer; has grown from 10 employees to more than 25; and has steadier income than when it relied on seasonally variable retail sales. The plant is located on the coast, up to 3 hours' drive for many producers in the state, but its customer base is growing; some producers collaborate on livestock transport and product delivery to urban markets in the middle of the state. NC Choices' experience with AMSF laid the groundwork for future technical assistance for existing processors and facilitation of producerprocessor relationships.

The second project focused on the needs of buyers to help them pull more product through the supply chain. From 2008 to 2010, NC Choices partnered with Weaver Street Market (WSM), the state's largest natural foods cooperative, on a pilot project to expand wholesale market opportunities for local meats. NC Choices recruited producers and WSM committed to purchasing whole animals, which it receives from a small, local processor as quarter carcasses; WSM butchers cut and wrap the meat for the co-op's three retail stores. The project increased WSM's weekly sales of local grass-fed beef and pastured pork 150 percent (North Carolina State University [NCSU], n.d.). Yet expanding this model to other wholesale buyers was difficult because most restaurants, food service, and retail grocers lack the equipment and expertise to buy whole carcasses from producers and coordinate with processors.

The third project addressed this gap. In 2010, with start-up funding from the Kellogg Foundation, NC Choices created and then spun off a forprofit business to aggregate, distribute, and market local, pasture-raised meats. The company, now Firsthand Foods, works with two small USDAinspected processors and markets and provides weekly distribution of fresh and value-added pasture-raised meats, sourced from more than 40 North Carolina producers, to 60 customers including restaurants, specialty retailers, natural grocers, mobile markets and food trucks, and institutional food service providers (CEFS, 2013). It has three employees and had an estimated US $\$ 1$ million in sales in 2013.

Based on these experiences across the local meat supply chain, NC Choices made two strategic decisions. The first was to create a formal venue for farm-to-plate learning and networking, with particular focus on processing. NC Choices hosted the first Carolina Meat Conference in 2011, for producers, processors, marketers, consumers, regulators, and others involved with local meat supply chains. Sessions covered production, producerprocessor collaboration, marketing, meat cutting, animal handling, and on-farm poultry slaughter. More than 300 people from 13 states attended. Local processors, who had been "holding their cards pretty close to the chest, not ready to invest," in local meat, left the conference with new awareness about the potential market opportunity, 
according to NC Choices staff. In 2012, NC Choices created the Carolina Meat Institute (CMI) to offer workshops by national experts on growing a meat business, carcass breakdown, charcuterie, and related topics. To date, more than 700 participants from 16 states have attended CMI workshops.

The second strategic decision was to focus more time and resources on education and technical assistance for processors. As in Vermont, an important insight was that expanding local meats required understanding the actual capacity and constraints of existing processors who could potentially process for local producers but were not yet set up to do so. Curtis explained, "Everyone says we don't have enough. But we're not really clear what we do have and how much more we really need. How can we optimize existing processors and meet their needs?" The more they talked to small, local processors, the more they learned about the barriers to expansion: a lack of year-round commitment from producers; limited business development support, capital assets, and employee training opportunities; and high staff turnover. Processors were also reluctant to invest in expansion or new services for local producers without assurances that local meat was more than a passing trend (NC Choices, 2012). Casey McKissick, current program director, explained, "We kept getting calls about business plans for new processing plants. But we kept saying, what about the processors who are already in business? What can we do for them?"

NC Choices designed a technical assistance program that would target processors' specific needs and started with a small, custom-exempt plant. The co-owners were experienced butchers who had worked with producers and freezer-meat customers for many years. Yet their customexempt status meant the meat could not be sold. “They weren't aware of the industry's growth and consumer demand for local and niche meats or how to capture more of the processing business for producers who direct market," McKissick explains. "The Carolina Meat Conference lit a fire under them" (NMPAN, 2012, para. 3). In 2012, with NC Choices' help, the butchers made progress quickly: they bought a computer and learned Excel, word processing, and email; applied for a USDA grant of inspection; wrote a customer manual; applied for cost-share grants for value-added equipment and a new facility for handling live animals; and hosted an open house for new customers, which drew 70 people from seven counties.

Based on this experience, NC Choices applied for and received a grant from the North Carolina Rural Center to launch, in early 2013, a Meat Processors Business Development Assistance Program to offer similar hands-on assistance to other small processors with a focus on business development and technical training. ${ }^{2}$ Processors applied to be part of the program, and projects were selected based on their potential to enhance the state's local meat-processing capacity. The first round of projects, underway as of this writing, include improving operational flow and efficiency, design of cloud-based Hazard Analysis Critical Control Point (HACCP) management systems, accounting training, cutting tests, staff training for value-added product expansion, and figuring out whether a local grocery-store butcher counter could costeffectively offer state-inspected cut and wrap services to producers. Project results will be reported in 2014, along with a best practices manual written for both processors and other current or potential technical assistance providers; this second audience reflects NC Choices' commitment to help peer organizations learn from its experiences with this complex, challenging project.

While the efforts described above have been led by NC Choices, they are in fact the product of multiple partnerships with public and private agencies, organizations, and businesses. Reflecting the partnership structure of its parent, CEFS, NC Choices is deliberately not an independent actor but the active center of statewide collaboration. For example, an important and ongoing partner is the North Carolina Department of Agriculture's Meat and Poultry Inspection Division (MPID). MPID has worked with NC Choices to reduce regulatory confusion for producers and processors related to processing and marketing of local meat; survey the state's processors about the range of services they offer producers (North Carolina

${ }^{2}$ Disclosure: Author Gwin is a consultant on this project. 
Department of Agriculture and Consumer Services [NCDACS], 2011); and even create supportive policy: NC Choices collaborated with MPID to change the annual limit for on-farm poultry slaughter from 1,000 to 20,000 birds and then educate producers about the new rules and market opportunities.

\section{New York: Northeast Livestock Processing Service Company}

In New York State, an independent, for-profit service company has provided important leadership to strengthen local meats processing, both statewide and in the broader Northeast region. What began as an innovative approach to improving producer-processor relationships and access to processing has evolved into a marketing and distribution company that continues to support both producers and processors. As described below, this work complements university cooperative extension programming that helps producers with niche meat production and marketing, including navigating processing regulations.

The Northeast Livestock Processing Service Company (NELPSC) was conceived in 1999 as a way to bridge the gap between producers and processors. Producers who sold sides and quarters were increasingly having trouble getting their animals processed; the need grew as the local food movement and by-the-cut sales of local meats escalated in New York. Keith DeHaan, a livestock processing consultant funded by the Rockefeller Foundation to do a feasibility study for new processing capacity in the state, realized that capacity itself was less the limiting factor than the ability of local producers to establish and maintain working relationships with existing processors. He proposed a fee-for-service company that would help member producers identify processors, schedule processing dates, give clear cutting instructions, and develop good working relationships for the long term. NELPSC was officially established in 2005 by the Hudson-Mohawk Resource Conservation and Development Council, with a US $\$ 52,000$ grant from the New York Department of Agriculture and Markets (Munger, 2008). It is a limited liability corporation (LLC) with an allproducer board of directors and one full-time paid employee, Processing and Marketing Coordinator Kathleen Harris.

The company's original mission was what Harris calls "processing facilitation." For a onetime fee of US $\$ 50$, NELPSC matches producers with processors that meet their needs (location, pricing, services provided); schedules slaughter dates; and conveys cutting instructions. For an additional fee, because of the time required, Harris provides quality-control oversight in the plant when a producer's livestock are being processed. The approach is effective in developing strong producer-processor relationships: after the first few years, most producers are able to work directly with their processors without NELPSC's assistance. In 2012, NELPSC had more than 130 producer clients and working agreements with 11 processors, both USDA-inspected and statelicensed, custom-exempt.

Harris then turned her attention to a different set of producers asking for help: those who wanted to sell into local, niche markets but did not want to do the marketing themselves. In a move similar to NC Choices' launch of Firsthand Foods, in 2008 NELPSC started Local Foods from Local Farms, a marketing and distribution company that aggregates product from multiple producers and sells to wholesale buyers, primarily privates schools and universities. Harris finds buyers, takes orders, and puts a call out to her producer members to select livestock, mostly grass-fed beef culls, to fill those orders. She arranges for slaughter and processing at one of the federally inspected, third-party audited plants NELPSC works with regularly and delivers orders in the NELPSC refrigerated truck. Producers pay a fee, based on hanging weight, to cover the cost of these services. Harris sells only wholesale, to avoid competing with producer members. She notes, "We sell where they can't sell for themselves."

Until 2010, NELPSC subsidized its processing facilitation services with grants from the NY Farm Viability Institute and private foundations. In 2010, revenue from Local Foods from Local Farms allowed NELPSC to become financially selfsustaining. Taking on marketing and distribution allowed NELPSC not only to help producers access new markets but also to become a key 
customer for its member processors, providing steady throughput in higher volumes than individual producers can typically deliver.

As a for-profit company, NELPSC is directly responsible to its members, but its work has strengthened the local meats processing landscape across the state and region. From a farm-to-plate perspective, the processing facilitation in particular complements the work of another key nonmarket actor in the region, Cornell University Cooperative Extension, on sustainable livestock production and local meats marketing. Cornell publishes a guide to niche meat marketing that includes processing regulations, moderates a regional email list on local meat production and processing, and works directly with the state agriculture agency and the USDA Food Safety and Inspection Service to clarify regulatory questions for producers and small processors. To facilitate sales of farm-direct freezer meat, the university developed an online marketing platform, MeatSuite, and is building two freezer unit facilities that will function as old-style meat lockers that consumers can rent to store meat they purchase in bulk from local producers (LeRoux, 2013).

All of this work together has helped underwrite a significant expansion of processing capacity for local meats in the region over the last decade. New USDA-inspected plants have been built, custom-exempt plants have transitioned to inspection, and producers have built their own retailexempt, state-licensed cut and wrap plants (Harris, 2013). None of it would have happened without entrepreneurial producers and processors, and consumer to buy the product, but NELPSC, Cornell, and other agencies and organizations have provided essential support.

\section{National Networking for Shared Learning and Innovation}

The three regional collaborations discussed so far are rooted in local context and conditions. They also benefit from connecting, on a national basis, with other individuals and entities, public and private sector, with expertise and experience related to local meats processing. The Niche Meat Processor Assistance Network (NMPAN) was created in 2007 to facilitate such connections.
NMPAN began as primarily an online information hub, both collecting and generating relevant resources, but has evolved into an active peerlearning community that fosters and diffuses innovation. In Wolf's terms, NMPAN combines a reference network with a professional structure that links institutional entrepreneurs with processors, producers, and other businesses in local meat supply chains. Interactions occur largely by phone, an email list, webinars, and occasional inperson meetings. The network includes university faculty, primarily cooperative extension; federal, state, and local agencies; nongovernmental organizations ranging from meat processor trade associations to sustainable agriculture advocacy groups; and producers, meat and poultry processors, marketers, and buyers. NMPAN's advisory board, which meets monthly by phone, is drawn from industry, academia, nonprofit organizations, and government, including the USDA Food Safety and Inspection Service (FSIS) Small Plant Outreach Office. The two authors of this paper created and coordinate NMPAN.

In its first phase, from 2007 to 2011, NMPAN focused on collecting and creating practical resources related to local meats processing (e.g., processor case studies, business planning and management tools, simple guides to regulatory requirements, mobile slaughter unit videos and guidebook), made available online; start-up funding (US $\$ 300,000$ over five years) was provided by the Kellogg Foundation, Heifer International, USDA Rural Development, and the eXtension Imitative. With this reference network of resources now largely in place, two distinct but linked sites of shared learning and innovation have emerged. The first is the NMPAN email list, where processors and producers ask and answer technical questions related to many aspects of plant operations, from plant design, wastewater systems, and equipment selection, to food safety, HACCP, and third-party audits and to product and cutting quality. Online interactions may continue by phone, with one processor advising another about refrigeration or setting up an apprenticeship program. In 2013, NMPAN coordinators began to facilitate this deeper interaction more actively by creating an informal peer-consulting network for processors 
who would prefer to learn from their peers "another guy with his name on the front door" (although they are not always guys) — than from professional consultants or suppliers.

Shared learning and innovation diffusion also occurs among nonmarket actors in the network, most actively during monthly advisory board phone calls; the NMPAN Advisory Board includes representatives from all three regions discussed above. Advisors bring their specific projects and ideas to the calls for group brainstorming and suggestions. The different regions are, in a sense, a laboratory to test ideas and approaches. Advisors attend and speak at each other's conferences, often bringing processors from their regions; the $\mathrm{New}$ England Meat Conference was inspired by and modeled after the Carolina Meat Conference. In parallel with the peer-consulting network, the advisory board is now strategizing how to create "management teams" - small groups of experienced small processors, consultants, and potentially producers, perhaps recruited from each other's regions - that would provide first start-up support and then long-term mentoring for motivated but inexperienced new plant operators.

The group is also a valuable sounding board for frustrations and a source of guidance when projects unravel, partners pull out, and plans shift in unexpected ways. For example, a processor who could potentially provide valuable processing to local producers may ask for technical assistance to do so but then be unwilling to make any recommended changes: the priorities of a specific business may not match broader food system goals. Advisory board members help each other decide if, when, and how to end or overhaul projects.

The two professional structures are overlapping and have fluid boundaries. Interactions with practitioners, from email list discussions to meetups and plant tours at processing conventions, are highly instructive for advisory board members and other similar nonmarket actors in the network, in order to learn about the technical, regulatory, and business environments in which these processors operate. Advisors and other assistance providers have recruited NMPAN member processors as expert consultants. New knowledge and resources generated by advisory board members - together or in their home regions - can be circulated to the broader NMPAN network, including initiatives described above. The more tacit this knowledge is, the harder it is to disseminate without practical interaction, and regions with supportive nonmarket actors who can make knowledge from elsewhere relevant to local conditions appear more likely to benefit.

\section{Conclusion}

The efforts we have described appear to have had a significant and positive impact on local meat processors and local meat supply chains. They involve different types of public agencies, both regulatory and development-focused; different types of nonprofits, from trade associations to advocacy groups; universities, primarily cooperative extension; and even, as in New York, for-profit entities. They use a variety of approaches: technical training and assistance, regulatory clarification and education, targeted investment, peer learning and communication, and other mechanisms to support not only individual businesses but also the commitments between them.

These efforts, we suggest, are vibrant examples of institutional entrepreneurship: they harness resources, catalyze collaboration, and spur action that otherwise would not have happened. They are also transformative, helping shift not only how producers and processors work together, but also how their own agencies and organizations engage with local meats as a subset of local food. Their processing-related work is done explicitly within a farm-to-plate context, nested within work that spans local meat supply chains and demands cooperation and interaction along the entire chain. These institutional entrepreneurs are working to analyze and then address the perceived lack of processing from the processor's perspective, rather than accepting the conventional notion that simply building more processing plants will grow the local meat sector. They foster innovation by cooperating with each other, as working groups or loose collaborations, not only in their regions but nationally: they learn from and co-create new knowledge and strategies with their peers in different regions. They share successes and failures, big ideas and rabbit holes. Their ability to connect and collaborate with 
their peers in other regions strengthens their ability to support transformative learning in their home regions. As other farm-to-plate approaches to increase the extent of local meats emerge elsewhere in the country (e.g., Barry \& Pirog, 2013), they are using NMPAN to connect with peers, trade ideas, and learn from each other's experiences.

Enhanced commitments between processors and their producer-customers are still fundamental to the persistence and expansion of local meats. No amount of institutional entrepreneurship can fill the gap if processors do not have enough livestock to process enough of the year to cover both their operating and fixed costs and earn at least some profit. As demonstrated in this paper, however, nonmarket actors, as institutional entrepreneurs, can help both producers and processors change how they have traditionally worked together and move toward more committed relationships, from improved communication to aggregation, distribution, and marketing. Government agencies, universities, nonprofit organizations, and others can support the local meat sector through research, technical and regulatory assistance, investment, and facilitating connections and peer-to-peer learning focused on local meats processing.

Recommendations for Practitioners: Agencies, Nonprofits, Universities, and Other Nonmarket Actors

The institutional entrepreneurs described here and the approaches they are taking provide, to some degree, recommendations for what can be done and how to do it. Targeted technical assistance and training on a range of topics, from food-safety regulatory compliance to order and inventory management, can build capacity for both processors and their producer-customers. Needs and opportunities, and therefore the strategies and tools to address them effectively, will vary from region to region. Yet a few recommendations that follow are applicable across regions.

Above all, when local meats processing emerges as an issue of concern, it is critical that existing processors are not only informed but also actively consulted about their own concerns, constraints, ideas, and opportunities. This often requires not only inviting them to the table (bringing processors to producer meetings) but going to their table (bringing producers to processor trade association meetings). Educational events should be designed and delivered to encourage shared learning among producers and processors. Not all processors will wish to participate, and others may start and then change their minds, but proposed innovations in local meats processing must have buy-in from at least some local meat processors to work.

Second, a wide range of technical assistance and capacity-building can help strengthen local meats processing, related to business and management skills, grant-writing, transitioning to USDA inspection or third-party certification, operational flow and efficiency, regulatory compliance, customer service, and other topics. Institutional entrepreneurs can also bring innovative and successful systems from other regions and businesses. For example, scheduling is a common challenge for both producers and processors: producers may have to book slaughter spots long in advance, yet processors often have costly no-shows that leave employees and equipment idle. Institutional entrepreneurs can help producers and processors adapt and implement innovative, proven scheduling systems (as discussed in Gwin et al., 2013). Because a new approach to scheduling is likely to require additional commitment on both sides, primarily time and mental energy, institutional entrepreneurs can provide critical support and encouragement in the early months as the new approach gains traction and proves its value.

Third, while efforts to change federal meat and poultry inspection law and policy to favor small, local processors have gained little traction (Gwin \& Thiboumery, 2013), other policy strategies have been effective and are replicable. Examples include clarifying and adjusting state- and county-level administrative regulations (e.g., interpretations of federal poultry processing exemptions and U.S. Food and Drug Administration (FDA) Food Code variance requirements for cured meats); establishing tax incentives or loan guarantees for plant and equipment upgrades; and working with state and local agencies to allow innovative wastewater and offal management systems proven to work else- 
where (e.g., Bonhotal \& McGarva, 2009; Chivers \& Gunthorp, 2013). As demonstrated in Vermont, state agencies can offer valuable support by allocating staff time to work on these issues, to provide not only technical assistance to individual plants but statewide leadership on industry-scale challenges and solutions.

\section{Suggestions for Future Research}

Applied research is needed on a wide range of topics, which many nonmarket actors and cooperative extension faculty in particular may be well positioned to address. Research targeting specific aspects of small processing businesses could help enhance capacity and profitability:

- Scale-appropriate food safety strategies: While all plants, regardless of size, must ensure that meat and poultry are produced safely, effective interventions can be designed that work well in a small plant environment (e.g., Flowers \& Cutter, 2005). Recently stepped-up emphasis by federal regulators on validation of interventions within the HACCP system makes this need even more pressing: small plants need access to more "safe harbor" process guidance (e.g., USDA, 1999a; 1999b).

- Increasing operational efficiency: Constraints analysis has proven effective in helping small processors ease bottlenecks without the considerable investment required to add floor space or build a bigger facility (e.g., McCann, 2011). Additional research that proves the value of this approach in a small plant environment should be paired with an educational and outreach strategy targeting small plants.

- Byproducts: For large, conventional processors, "the drop" (heads, hides, hooves, bones, fat, blood, and offal) is their primary source of revenue, often more so than meat; they can collect and refine byproducts at large enough volumes to access valuable international markets. For small processors, the drop is typically a liability, not a revenue stream. A few small processors have experimented with on-site composting, bioenergy generation, and small-scale incineration. Yet to be explored is the possibility of processor collaboration on a regional scale for shared byproduct collection, refinement, and marketing.

All of these are practical topics that rest on the assumption that strengthening processing infrastructure for local meats is a good idea. Yet a broader question about what we are seeing in local meats processing also demands attention. While energy and enthusiasm for local meats and local meats processing are high now (at least in some areas), what of the long run? A limitation of our research is that it describes initiatives occurring over a relatively short period of time and provides only short-term, though positive, evidence of their value. How is the processing landscape evolving (or not) to meet the needs of local meat producers and marketers, not only now but in the future? Are these changes increasing the availability of local meats and the profitability of producers and their supply chain partners? Will current interest in local meats - in its $21^{\text {st }}$ century version, far beyond "locker" or "freezer" meat sales — not only persist but grow enough to support new infrastructure investments? Anecdotal evidence suggests that in many parts of the country, new small processors are opening or being planned, and existing processors are making changes, all in response to apparent demand for local meat processing services. As small businesses in a high-cost, thinmargin industry, they face tough odds. Significant, stable commitments from producers, both livestock and financial investment, will be critical to their long-term survival. Longitudinal research to track the trajectory and evolution of these businesses, both as a sector and through in-depth case studies, would yield important insights about how to design and maintain resilient infrastructure for local foods.

\section{Acknowledgements}

The Economic Research Service of the U.S. Department of Agriculture provided partial funding support for this research. The authors wish to thank the five advisors 
and two research assistants involved with the project; the many people we interviewed and worked with over the course of the project; the Niche Meat Processor Assistance Network Advisory Board; and the five anonymous JAFSCD reviewers who provided helpful suggestions and insightful comments on the manuscript.

\section{References}

Barry, J., \& Pirog, R. (2013). Supplying local and regional markets: Challenges and solutions for the Michigan-based meat and livestock value chains. East Lansing, Michigan: Michigan State University, Center for Regional Food Systems. Retrieved from http:// foodsystems.msu.edu/uploads/file/resource s/livestock-stakeholders-report.pdf

Bloom, J. D., \& C. C. Hinrichs. (2010). Moving local food through conventional food system infrastructure: Value chain framework comparisons and insights. Renewable Agriculture and Food Systems, 26(1), 13-23. http://dx.doi.org/10.1017/S1742170510000384

Bonhotal, J., \& McGarva, R. (2009, December 1). Alternatives to rendering: Butcher waste composting [Webinar]. Retrieved from: http://www.extension.org/pages/24718/alternativ es-to-rendering:-butcher-waste-composting

Buck, M. (2011). Strategic considerations for investment in sustainable agriculture and local/community food systems in Oregon. Portland, Oregon: Meyer Memorial Trust. Retrieved from http://www.mmt.org/sites/default/files/FullCFS report.pdf

Cantrell, C., \& Lewis, R. (2010). Food system infrastructure: Michigan Good Food Work Group Report No. 5 of 5. East Lansing, Michigan: Michigan State University, C.S. Mott Group for Sustainable Food Systems. Retrieved from http://www.michiganfood.org/ assets/goodfood/docs/Food System Infrastructure Report.pdf

Center for Environmental Farming Systems [CEFS]. (2012, September 4). About CEFS. Center for Environmental Farming Systems Web site. Retrieved from http://www.cefs.ncsu.edu/aboutcefs.html

CEFS. (2013). Farmhand Foods has a new name. CEFS E-News, June 2013. Retrieved from http://www.cefs.ncsu.edu/newsevents/news/2013 Ljune-news/firsthand-foods.html
Chivers, C., \& Gunthorp, G. (2013, July 23). Innovations in wastewater management [Webinar]. Niche Meat Processor Assistance Network. Retrieved from http://www.extension.org/pages/ 68667/innovations-in-wastewater-management-forsmall-meat-processors

DeHaan, K., \& Raines, C. (2011, September 28). To build or not to build: Lessons learned from new processing ventures [Webinar]. Niche Meat Processor Assistance Network. Retrieved from http://www.extension.org/pages/59962/to-buildor-not-to-build:-lessons-learned-from-newprocessing-ventures

Dunning, R., Creamer, N., Massey Lelekacs, J., O’Sullivan, J,. Thraves, T., \& Wymore, T. (2012). Educator and institutional entrepreneur: Cooperative Extension and the building of localized food systems. Journal of Agriculture, Food Systems, and Community Development, 3(1), 99-112. http://dx.doi.org/10.5304/jafscd.2012.031.010

Fairfax, S. K., Dyble, L. N., Guthey, G. T., Gwin, L., Moore, M., \& Sokolove, J. (2012). California cuisine and just food. Cambridge, Massachusetts: MIT Press.

Flowers, S. L., \&Cutter, C. N. (2005). Antimicrobial spray treatments for red meat carcasses processed in very small meat establishments. University Park, Pennsylvania: Pennsylvania State Department of Food Science, Texas Tech University Department of Animal Science and Food Technology, \& Washington State University Department of Food Science and Nutrition. Retrieved from http://www.meathaccp. wisc.edu/validation/assets/acid spray intervention booklet from Penn State 2005.pdf

Food \& Water Watch. (2009). Where's the local beef? Rebuilding small-scale meat processing infrastructure.

Retrieved from http://documents.foodandwater watch.org/doc/Wheres'TheLocalBeef.pdf

Fromartz, S. (2012, October 7). Local slaughterhouses come back to life [Web log]. Piedmont Environmental Council of Virginia. Retrieved from http://www.buylocalvirginia.org/index.cfm/1,30,6 40,0,html/Local-slaughterhouses-come-back-to-life

Goodsell, M., \& Stanton, T. (2011). A resource guide to direct marketing livestock and poultry. Ithaca, New York: Cornell University Cooperative Extension. Retrieved from http://smallfarms.cornell.edu/ resource-guide-to-direct-marketing-livestock-andpoultry/ 
Gwin, L., \& Thiboumery, A. (2013). Local meat processing: Business strategies and policy angles. Vermont Law Review, 37, 987-1006.

Gwin, L., Thiboumery, A., \& Stillman, R. (2013). Local meat and poultry processing: The importance of business commitments for long-term viability (Economic Research Report No. ERR-150). Washington, D.C.: U.S. Department of Agriculture, Economic Research Service.

Harris, K. (2013, March 23). How farmers work successfully with processors. Presentation at the New England Meat Conference, Concord, New Hampshire.

Hinrichs, C., \& Charles. L. (2012). Local food systems and networks in the US and the UK: Community development considerations for rural areas. In M. Shucksmith, D. L. Brown, S. Shortall, J. Vergunst, \& M. E. Warner (Eds.), Rural transformations and rural policies in the US and UK (pp. 156-176). New York: Routledge.

Holcomb, R. B., Flynn, K., \& Kenkel, P. (2012). A feasibility template for small, multi-species meat processing plants. Journal of Extension, 50(5), 5TOT11. Retrieved from http://www.joe.org/joe/2012october/tt11.php

Johnson, R., Marti, D., \& Gwin, L. (2012). Slaughter and processing options and issues for locally-sourced meat (LDPM-216-01). Washington, D.C.: USDA Economic Research Service. Retrieved from http://www.ers.usda.gov/media/820188/ldpm21601.pdf

LeRoux, M. (2013). Reviving the meat locker in New York State. Retrieved from the eXtension website: http://www.extension.org/pages/69089/revivingthe-meat-locker-in-new-york-state

Lewis, C. B., \& Peters, C. J. (2011). A capacity assessment of New England's large animal slaughter facilities as relative to meat production for the regional food system. Renewable Agriculture and Food Systems, 27(3), 192-199. http://dx.doi.org/10.1017/S1742170511000305

Low, S. A., \& S. Vogel. (2011). Direct and intermediated marketing of local foods in the United States (Economic Research Report No. ERR-128). Washington, D.C.: U.S. Department of Agriculture, Economic Research Service.

Maguire, S., Hardy, C., \& Lawrence, T. B. (2004). Institutional entrepreneurship in emerging fields: HIV/AIDS treatment advocacy in Canada. Academy of Management Journal, 47(5), 657-679.

http://dx.doi.org/10.2307/20159610

Martinez, S., Hand, M. S., Da Pra, M., Pollack, S., Ralston, K., Smith, T.,... Newman, C. (2010). Local food systems: Concepts, impacts, and issues (Economic Research Report No. ERR-97). Washington, D.C.: USDA, Economic Research Service Retrieved from http://www.ers.usda.gov/publications/erreconomic-research-report/err97

McCann. N. (2011). Processors: Have you tried daily slaughter? Niche Meat Processor Assistance Network E-

Update. Retrieved from http://www.extension.org/ pages /61709/processors:-have-you-tried-dailyslaughter

Morley, A., Morgan, S., \& Morgan, K. (2008). Food hubs: The "missing middle" of the local food infrastructure? Cardiff, Wales, UK: BRASS Centre, Cardiff University. Retrieved from http://www.ngfn.org/resources/ngfndatabase/knowledge/Food HubKM0908.pdf

Munger, Jr., E. (2008, August 30). Broker helps local beef farmers: Colleges a market for grass-fed product. Daily Gazette [Schenectady, New York]. Retrieved from http://www.dailygazette.com/ news $/ 2008 / \mathrm{aug} / 30 / 0830$ beef

NC Choices. (2012). NC Choices'Meat Processors Business Development Assistance Program request for applications. Old Fort, NC: NC Choices MPBDA Program. Retrieved from http://sfc.smallfarmcentral.com/ dynamic content/uploadfiles/882/MPBDA $\% 20$ Program \%20Application \%20FINAL.pdf

Niche Meat Processor Assistance Network [NMPAN]. (2012, January). Hands-on technical assistance for North Carolina processor. NMPAN E-Update. On file with author.

North Carolina Department of Agriculture and Consumer Services [NCDACS]. (2011). Directory of establishments inspected by NCDA\&CS Meat and Poultry Inspection Division: Willing to process products for individuals starting a new business. Siler City, North Carolina: NCDA\&CS Retrieved from http://www.ncagr.gov/meatpoultry/Business/ New $\% 20$ Business $\% 20$ by $\% 20$ County.pdf

North Carolina State University [NCSU]. (n.d.). Weaver Street Marketing Retail Pilot. Retrieved from http://ncchoices.ces.ncsu.edu/marketing-pasturedmeats-2/weaver-street-marketing-retail-pilot/ 
Raines, C. (2011, September 28). Whatever works [Webinar]. Retrieved from eXtension website: http://www.extension.org/pages/59962/to-buildor-not-to-build:-lessons-learned-from-newprocessing-ventures

Thiboumery, A. (2008). Making ends meat: Using communities of practice to revitalize the decentralized meat processing sector in Iowa and beyond (Unpublished doctoral dissertation). Iowa State University, Ames, Iowa.

U. S. Department of Agriculture [USDA]. (n.d.). Know Your Farmer, Know Your Food Compass.

Retrieved from http://www.usda.gov/wps/ portal/usda/usdahome?navid=KYF_COMPASS

USDA. (1999a). Compliance guidelines for meeting lethality performance standards for certain meat and poultry products. Washington, D.C.: USDA, Food Safety and Inspection Service. Retrieved from http://www.fsis.usda.gov/oa/fr/95033f-a.htm

USDA. (1999b). Compliance guidelines for cooling heat-treated meat and poultry products (stabilization). Washington, DC: USDA, Food Safety and Inspection Service. Retrieved from http://www.fsis.usda.gov/oa/fr/95033F-b.htm USDA. (2013). FSIS compliance guideline: HACCP systems validation. Washington, D.C.: USDA Food Safety and Inspection Service. Retrieved from http://www.fsis.usda.gov/shared/PDF/HACCP_ Systems Validation.pdf
University of California Cooperative Extension. (2013). Agenda. 2013 California Meat Summit. Agenda for March 27 conference, University of California Cooperative Extension, Placerville, California. Retrieved from http://ucanr.edu/sites/Roger Livestock/2013 California Meat Summit/

Wenger, E., McDermott, R., \& Snyder, W. M. (2002). Cultivating communities of practice: A guide to managing knowledge. Cambridge, Massachusetts: Harvard Business Review Press.

Western SARE. (2013). Western SARE's “Strengthening Agriculture's Infrastructure” Conference Edition. Simply Sustainable, 7(1), 1-28. http://www.westernsare.org/Conferences/Strengt hening-Agriculture-s-Infrastructure-Conference

Wolf, S. A. (2008). Professionalization of agriculture and distributed innovation for multifunctional landscapes and territorial development. Agriculture and Human V alues 25(2), 203-207. http://dx.doi.org/10.1007/s10460-008-9117-1

Zezima, K. (2010, March 27). Push to eat local food is hampered by shortage. New York. Times. http://www.nytimes.com/2010/03/28/us/ 28slaughter.html?pagewanted $=$ all \& $\mathrm{r}=0$

Zipparo, A., (2013, April 4). The women of the First Annual New England Meat Conference [Web log]. Women's Agricultural Network. Retrieved from https://blog.uvm.edu/wagn/2013/04/04/thewomen-of-the-first-annual-new-england-meatconference/ 